\title{
The Efficiency of a Solar Cooker in Pakistan's Quetta Region
}

\author{
Muhammad Ali Kakar, Jafar Khan Kasi*, Ajab Khan Kasi, Muzamil Bokhari, \\ Muhammad Latif, Muhammad Ayaz
}

Department of Physics, University of Balochistan, Quetta, Pakistan

Received: 8 July 2018

Accepted: 10 September 2018

\begin{abstract}
Many sun-rich countries of the world use solar energy for their daily cooking needs. Solar cooking is one of the most economical methods that decreases deforestation. The main purpose of this research is to find the different thermal performance parameters of a solar box cooker in the climatic conditions of Quetta, Pakistan (Latitude +30.21 and Longitude +67.02 ). The tested parameters were $F_{1}$ and $F_{2}$, cooking power, standard cooking power and efficiency $\eta$. Experimental tests were conducted to find the value of these parameters. The value of $F_{1}$ and $F_{2}$ were found to be 0.12 and 0.58 , respectively. Values of cooking power and standard cooking power were 40.33 and 37.06, respectively. A regression correlation was plotted graphically between standard cooking power $\mathrm{P}_{\mathrm{s}}$ and temperature difference $\Delta T$. The correlation coefficient was calculated as 0.80 . The overall efficiency of the box-type solar cooker was $29.81 \%$. The result shows that the climatic conditions of this area are suitable for solar cooking.
\end{abstract}

Keywords: solar energy, solar cooker, thermal performance, cooking power, efficiency

\section{Introduction}

Renewable energy is a type of energy derived from natural sources such as wind, rain, wave, geothermal, heat, tides and solar energy, etc. Renewable energy contributes approximately $19.2 \%$ to world energy consumption and $23.7 \%$ of electricity generation [1]. The top consumers of renewable energy around the world are: Sweden (54\%), Austria (62\%), New Zealand (65\%), Brazil (86\%), Norway (98\%) and Iceland (100\%) [2]. The total output energy of the sun in all directions is $3.8 \times 10^{20} \mathrm{MW}$. The earth receives only $1.7 \times 10^{14} \mathrm{~kW}$ of the total output energy of the sun [3]. The world's top

*e-mail: jafarkhankasi@gmail.com five countries in the generation of solar water heating at the end of 2013 were China, the United States, Germany, Turkey and Brazil. The growth rate of solar heating in 2013 was raised to $15.7 \%$ [4]. During the last five decades, different designs of solar energy devices were made in which the working fluids were heated to power mechanical systems. Central receiver systems use mirrors to focus the sun's energy onto the receiver. The temperature limit of the receiver is from $100^{\circ} \mathrm{C}$ to $150^{\circ} \mathrm{C}$ in the central receiver system [5]. The use of solar energy technologies has increased considerably during the last decade. It is a large amount of solar energy that can be utilized throughout the year [6]. A solar cooker basically uses solar energy to cook food. Many countries around the globe use solar cookers. Its usage increases as the prices of cooking fuel such as LPG, electricity, coal and kerosene increase. The use of solar cooking 


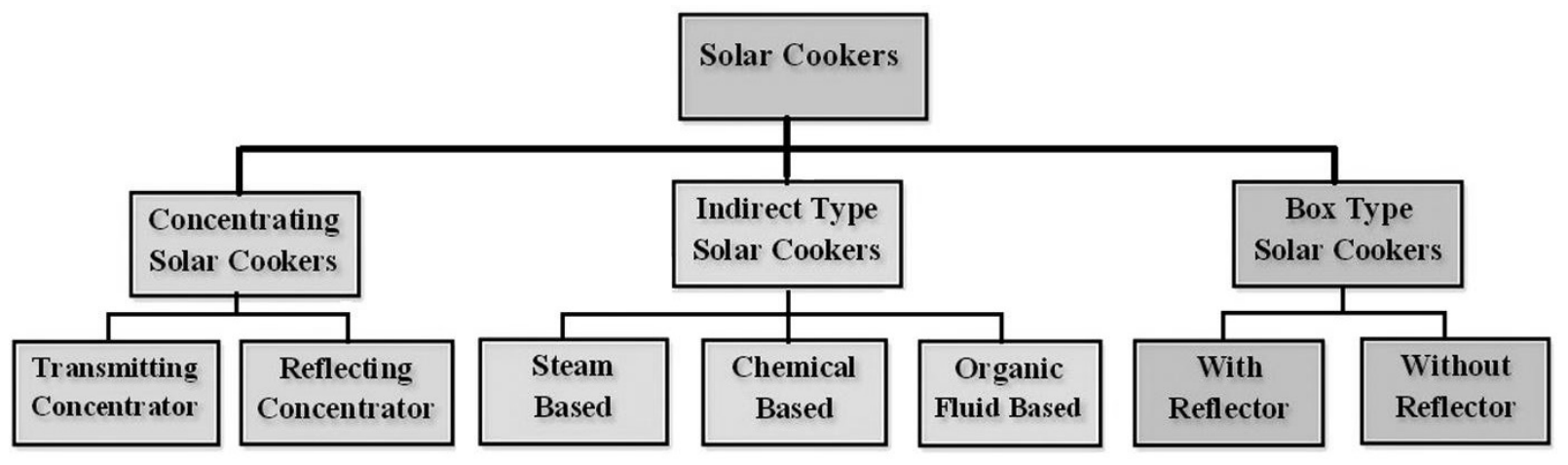

Fig. 1. Classification of solar cookers.

started in the $16^{\text {th }}$ century. Its use was increased during World War II due to fuel shortages. The importance of solar cooking is due to the high share of solar energy in world energy consumption [7]. Solar cooking has a large potential in the most populated countries, which have daily solar radiations of $5-7 \mathrm{kWh} / \mathrm{m}^{2}$ and have a large number of sunny days per year [8]. The solar cookers are broadly categorized into three different types, indirect type solar cookers, concentrating-type solar cookers and box-type solar cookers (non-concentratingtype solar cookers) as shown in Fig. 1.

A box-type solar cooker is simply a box having a pair of transparent glass covers at its upper side and a reflector used to reflect solar radiation into the box. The inside of the box is coated black so as to absorb maximum solar radiation [9]. The transparent cover or glazing allows shortwave solar radiation and is opaque for longwave solar radiation coming from the inner side of the solar cooker. Hence a solar box cooker (SBC) acts as a greenhouse. Different modifications have been made in SBC to enhance efficiency [10]. The SBC with two booster mirrors and transparent insulation materials (TIM) inserted in-between the pair of glazing can cook food in winter seasons [11]. The objective parameters have all the information related to a solar cooker. Due to these parameters, a solar cooker is suitable for a particular geographic location and climate [12]. Different designs of solar box cookers were formed and tested theoretically and experimentally in order to improve their performance. A type of SBC was designed to solve the problem of preheating. The base of the cooker acts as a lid and reduces the convective heat transfer [13]. The effective concentration ratio (ECR) may also be used to evaluate the impact of a reflector on the performance of SBC by conducting tests with and without a booster mirror. A decrease in the boiling time was observed with the booster reflector. The maximum plate temperature of $149^{\circ} \mathrm{C}$ was achieved with a reflector and the ECR was 1.330.0152 [14]. The solar box cooker with a glazed bottom and sides allows for heating the cooking pot, thereby reducing the cooking time of the food, and it cannot be affected by wind [15]. A black stone instead of an absorber tray was used to store solar energy. Hence they solved the problem of late evenings [16]. Different types of storage materials have been tested. Bayburt stone, which has a high specific heat capacity, is used as storage material in box-type solar cookers. The efficiency of a bayburt stone solar box cooker was $35.3-21.7 \%$, as compared to a conventional solar cooker in the range of 27.6-16.9\% [17]. Two different types of box solar cookers made up of the same materials with cylindrical and rectangular geometries were experimentally tested. The cylindrical model achieved greater temperature than the rectangular solar box cooker [18]. Sethi et al. designed a parallelpiped shape cooking pot for the winter season. The cooking pot increased the amount of heat transfer to the food. The first and second figures of merit of a box-type solar cooker with this novel cooking vessel were 0.16 and 0.54 , respectively, compared with 0.14 and 0.43 for conventional plane cooking vessels. The cooking time was $37 \%$ less and cooking power was $40 \%$ more in a parallelepiped-type cooking vessel [19]. Hermim et al. designed a solar box cooker with a finned absorber plate, resulting in an increase in the heat transfer between the absorber plate and cooking pot, thus increasing the cooking time [20]. Guidara et al. designed a solar box cooker with four reflectors in order to achieve high temperature during low solar radiation. An increase in optical efficiency was observed. The first and second figures of merit ranged from 0.07-0.14 and 0.34-0.39, respectively. The final temperature of the absorber plate was 133.6 [21]. The solar box cooker was experimentally reported in different regions, achieving the utilizable efficiency of $26.7 \%$ and figures of merit $F_{1}$ and $F_{2}$, as 0.124 and 0.558 , respectively, satisfying the bureau of Indian standards. The efficiency was calculated to $32.7 \%$ for the same load [22, 23]. A box-type solar cooker was designed with internal reflecting mirrors and sloped top glazing. The maximum temperature of $150.5^{\circ} \mathrm{C}$ was achieved at standard solar radiations of $1000 \mathrm{~W} / \mathrm{m}^{2}$ and at $25^{\circ} \mathrm{C}$ ambient temperature [24].

\section{Mathematical Expressions of the Box-Type Solar Cooker}

If $\mathrm{Q}_{\text {in }}$ is the input energy of solar radiation for cooking time and $\mathrm{Q}_{\mathrm{F}}$ is cooker output energy (increase 
of energy of water) for the equation for the efficiency of the box type solar cooker $(\eta)$ will be [25]:

$$
\eta=\frac{Q_{F}}{Q_{\text {in }}}
$$

For constant solar normal radiation $I_{N R}$, collector area $A_{c}$, and cooking time $\Delta t$, it can be expressed as:

$$
\begin{gathered}
Q_{\text {in }}=I_{N R} A_{c} \Delta t \\
\text { and } Q_{F}=M_{\mathrm{w}} C_{\mathrm{w}} \Delta T
\end{gathered}
$$

The specific boiling time $t$ sepresents the time needed to boil $1 \mathrm{~kg}$ of water when the collector area is $1 \mathrm{~m}^{2}$, its unit is $\left(\mathrm{min} . \mathrm{m}^{2} / \mathrm{kg}\right.$ ), and characteristic boiling time $t_{c}$ for the mass of water $\mathrm{M}_{\mathrm{w}}$ are given by:

$$
t_{s}=\frac{\Delta t A_{c}}{M_{W}}, \quad t_{c}=\frac{t_{s} \bar{I}}{I_{N R}}
$$

The value of $I_{N R}$ is taken to be $900 \mathrm{~W} / \mathrm{m}^{2} . \bar{I}$ is the average solar insolation. The thermal test procedure of the box-type solar cooker, in terms of figure of merit by conducting no-load test and sensible heating test, is given by [26]:

$$
F_{1}=\frac{T_{p-T_{a}}}{\bar{I}}
$$

...where $\mathrm{F}_{1}$ is the first figure of merit, $T_{p}$ is the maximum plate surface temperature and $T_{a}{ }^{p}$ is the ambient temperature. The second figure of merit is obtained from the full load water heating test:

$$
F_{2}=F^{\prime} \eta_{0} C_{R}=\frac{F_{1} M_{w} C_{w}}{A \tau} \ln \left[\frac{1-\left(\frac{1}{F 1}\right)\left(T_{w 1}-\bar{T}_{a}\right) / \bar{I}}{1-\left(\frac{1}{F 1}\right)\left(T_{w 2}-\bar{T}_{a}\right) / \bar{I}}\right](6)
$$

$F^{\prime}$ is the heat exchange efficiency factor, $\eta_{0}$ is the optical efficiency, $C_{R}$ is the heat capacity ratio, $\mathrm{F}_{1}$ is the first figure of merit, $\mathrm{A}$ is the absorber plate area, $\tau$ is the time interval, $T_{w 1}$ and $T_{w 2}$ are the initial and final temperatures of water, $\bar{T}_{a}$ is the average ambient temperature and $\bar{I}$ is the average solar radiation. The cooking power of a solar box cooker is calculated as [27]:

$$
P=\frac{M_{w} C_{w} \Delta T_{w}}{\Delta t}
$$

...where $\mathrm{P}$ is cooking power, $\Delta T_{w}$ is the temperature difference of water and $\Delta t$ is the time interval. Funk also expressed the term standard cooking power, given by:

$$
P_{S}=\frac{700 M_{w} C_{w} \Delta T}{600 \bar{I}}
$$

...where $P_{S}$ is the standard cooking power, which is calculated for time interval $10 \mathrm{~min}$, and solar insolation $700 \mathrm{~W} / \mathrm{m}^{2}$ is used as reference illumination intensity level. For cooking time, an expression has been developed in terms of cooking power [12]:

$$
\tau=\frac{M_{w} C_{w}}{C_{3} N} \ln \frac{P_{S}\left(T_{w 1}\right)}{P_{S}\left(T_{w 2}\right)}
$$

...where $M_{\mathrm{w}}$ is mass of water, $C_{\mathrm{w}}$ is specific heat of water, $P_{\mathrm{s}(\mathrm{Tw})}$ is standard cooking power (the function of $T_{\mathrm{w} 1}$-initial temperature of water) and Ps $\left(\mathrm{T}_{\mathrm{w} 2}\right)$ is standard cooking power (which is the function of $T_{\mathrm{w} 2}$ - final temperature of water), $N$ is the number of pots, and $C_{3}$ is the coefficient that characterizes a cooker $\left(\mathrm{C}_{3}=0.3775\right)$. The efficiency ' $\eta$ ' of a solar cooker is calculated as [11]:

$$
\eta=\frac{\left(M_{w} C_{w}+M_{1} C_{u}\right)\left(T_{w 2}-T_{w 1}\right)}{C A \int_{0}^{\tau} I d t}
$$

...where $M_{w}$ is the mass of water, $M_{1}$ is the mass of cooking pot, $C_{u}$ is the specific heat of a cooking pot, $\mathrm{C}$ is the concentration ratio, $\mathrm{A}$ is the absorber plate area, $\tau$ is the time interval and $\mathrm{I}$ is solar insolation $\left(\mathrm{W} / \mathrm{m}^{2}\right)$. A different test procedure was used to find the design parameters to predict the thermal performance of a boxtype solar cooker [28]. A number of experiments were performed to find the values of $F_{1}$ and $F_{2}$. Regression analysis was used to calculate the optical efficiency $F^{\prime} \eta$. and heat capacity (MC)' of the box-type cooker. The purpose of this research is to find the performance parameters of a modified solar box cooker in Quetta, where no work has been done on solar cookers. The solar cooker was constructed with locally available low-cost materials, and some modifications have already been brought in the design as discussed by different researchers in the literature. Performance efficiency of a modified box-type solar cooker has been compared with the previously reported box-type solar cookers. The inclusion of fused glass and optimum gap between glazings will improve performance efficiency.

This paper tests solar cooking efficiency specifically in the Quetta region due to its proximity near the Afghanistan border, where many poor Afghan migrants reside. For them other energy sources are not financially bearable except to find wood, which adversely impacts the environment. In contrast, the utilization of a solar cooker is a green energy source with minimum cost. Moreover, in this region solar radiation is very high as compared to other parts of the world; most of the year sunny days and very less cloud/rain may also be advantageous for using solar cookers in the region.

\section{Experimental}

The schematic diagram of a box-type solar cooker used for experimentation is shown in Fig. 2. 


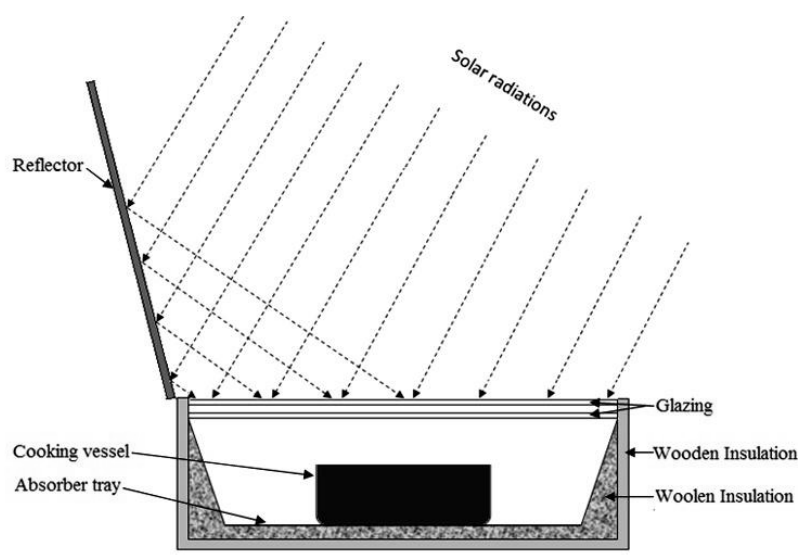

Fig. 2. Schematic diagram of a solar box cooker.

The inner dimensions of the cooker are $46 \times 46 \mathrm{~cm}$. The dimension of the absorber tray is $42.7 \times 42.7 \mathrm{~cm}$. It is painted black so as to absorb a greater amount of solar radiation. A gap of thickness $5.6 \mathrm{~cm}$ is formed between the sides of the cooker and the absorber tray. The gap is filled with insulation to stop heat losses from the cooker to atmosphere. At the top of the cooker we use double glazing, as shown in Fig. 3. Fused glass (Quartz) of thickness $1 \mathrm{~mm}$ is used as glazing, which does not stop any part of the solar spectrum such as ultraviolet, which increases the efficiency of a box-type solar cooker as compared to the conventional box-type solar cooker. The air gap between the two glazings was kept at a optimum distance of $0.5 \mathrm{~cm}$ in order to enhance the inner cooker temperature. A plane mirror of dimensions $51 \times 51 \mathrm{~cm}$ is mounted at the top of the solar cooker as a reflector (booster mirror), which reflects the incoming solar radiation, thus maximizing the solar flux. A mirror of $1 \mathrm{~mm}$ thickness is used which is thinner than the ordinarily used reflector. The reduced thickness minimizes the mirror absorption for sunlight, which also increases the efficiency of our designed solar cooker. A special type of cooking pot made of copper was used with diameter $21 \mathrm{~cm}$ and height $8 \mathrm{~cm}$ and is placed at the centre of the absorber plate, having close contact to the absorber plate so that high cooking temperature can be achieved by conduction. The thermal conductivity of copper is higher than in conventional aluminium and steel pots. The pot was blackened except for the bottom, which was polished mechanically in order to get a smooth surface and closed contact with the absorber tray. The cooking vessel was used with $2 \mathrm{~kg}$ of water in the thermal test procedure of a second figure of merit and cooking power. The experimental work was carried out to find the different performance parameters, which are necessary for different test procedures. Outdoor experiments were conducted to find the efficiency $\eta$ of the cooker. The experiments were also conducted to find $F_{1}$ and $F_{2}$ (first and second figure of merit) by conducting a no-load stagnation test and sensible heating test of a known load of water and the cooking power $\mathrm{P}$ and standard cooking power $P_{s}$.

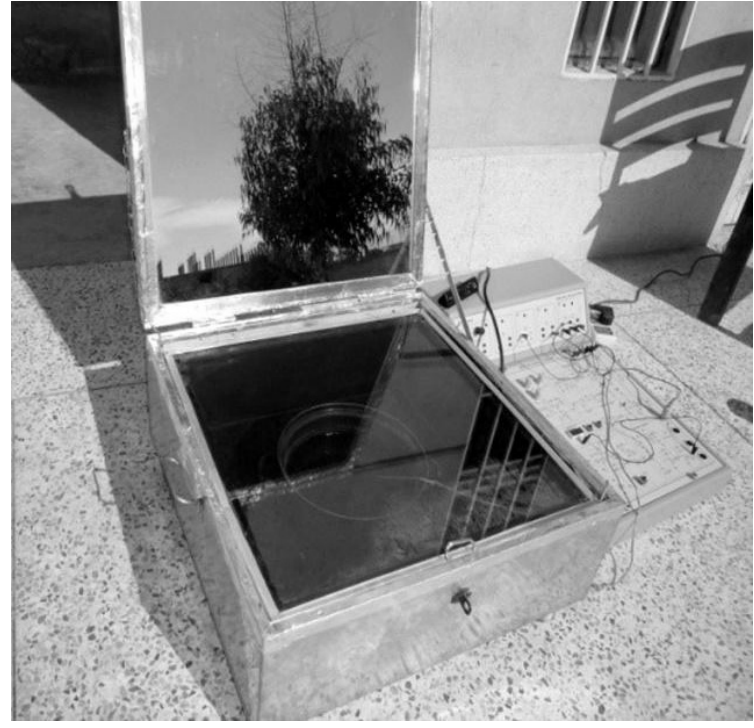

Fig. 3. Experimental setup and measuring devices.

During the experimentation, a pyranometer was used for measuring solar radiation on the horizontal surface. An anemometer was used to measure the wind speed, as the increase in the wind speed can affect the solar cooker performance. The digital thermometers were used to measure $T_{a}$ (ambient temperature) and a temperature transducer was used to measure temperature $T_{p s}$ (absorber plate temperature) and the temperature of water in the pot. A small hole was formed in the corner toward a rubber gasket to insert a thermocouple knob, which was connected to the temperature transducer digital trainer used for measuring plate temperature and pot content temperature. The hole was then sealed with silicone to stop heat loss through the hole. A data acquisition system was used to note temperature readings during the experiments.

\section{Testing Procedure}

Different thermal tests were performed to evaluate the performance of a box solar cooker in the climatic conditions of Quetta.

\section{No-Load Stagnation Test (First Figure of Merit)}

The solar cooker was kept outside in the sunshine with no pot inside the cooker. The probe of the thermocouple was fixed to the middle of the absorber plate so that it had great contact with the absorber tray. The thermocouple lead was sealed with silicone at the place where it was inserted. The output of the thermocouple was connected with a digital temperature controller to display the thermocouple readings. The reflector was removed during the test. The test started at 10:00 hours Pakistan standard time. During the test, the ambient temperature, absorber plate temperature and solar insolation were measured. The wind speed was also measured at the glazing level of the solar box 
cooker. After two hours the absorber plate of the solar cooker achieved maximum temperature (quasi steady state). At this stage (at the 10-minute period) there was a small change in temperature. At the quasi steady state the absorber tray temperature, the ambient temperature and solar radiation were recorded. This data was filled in Eq. (4) to find the value of $F_{1}$.

\section{Full-Load Test (Second Figure of Merit)}

In order to find the second figure of merit, a full load thermal test was conducted. The solar cooker was kept outside in the sun and the reflector was removed. A black-painted cooking vessel filled with $2 \mathrm{~kg}$ of water was placed inside the cooker. The thermocouple was used to measure water temperature. The probe of the thermocouple was fixed 5-10 $\mathrm{mm}$ above the base of the cooking pot. The lead of thermocouple was sealed with silicone. The test started at the same time (10:00 hours as for the first figure of merit). The measurements of ambient temperature, solar radiation and wind speed were taken at the level of the window of the solar box cooker. The temperature of water was measured at regular time intervals. This measuring process continued until the water temperature exceeded $95^{\circ} \mathrm{C}$. The initial and final temperatures were mentioned as $65^{\circ} \mathrm{C}$ and $95^{\circ} \mathrm{C}$, respectively, and the time interval between initial and final temperatures was recorded. The average ambient temperature and average solar radiation between $t_{1}$ and $t_{2}$ were calculated. The test was conducted on a clear day and the solar radiation was greater than $600 \mathrm{~W} / \mathrm{m}^{2}$.

\section{Cooking Power}

The solar box cooker was placed outside in the sunlight. The black cooking vessel was filled with $2 \mathrm{~kg}$ of water. The average water temperature was recorded at 10 -minute $(600 \mathrm{sec})$ intervals. The difference in the water temperature was calculated during each interval. The temperature difference was multiplied by the mass of water and specific heat capacity of water. The product was then divided by 600 s:

$$
P=\left(T_{2-} T_{1}\right) M_{w} C / 600 \mathrm{~s}
$$

The average water temperature, average ambient temperature and average solar radiation for every interval were recorded. In order to find the standard cooking power, the cooking power of every interval was multiplied to standard radiations of $700 \mathrm{~W} / \mathrm{m}^{2}$ and divided by the average solar radiation of the same interval, as given by:

$$
P_{S}=P\left(\frac{700}{\bar{I}}\right)
$$

To find the temperature difference, ambient temperature in every interval was subtracted from the average water temperature of the same interval as given by:

$$
T_{d=} T_{w}-T_{a}
$$

In every interval the standard cooking power was graphically presented against the temperature difference $T_{d}$ The intercept $\mathrm{W}$ and slope between the cooking power and temperature difference, i.e., $\mathrm{W} /{ }^{\circ} \mathrm{C}$ was found using linear regression. The coefficient of determination $\mathrm{R}^{2}$ was also found.

\section{Efficiency of Solar Cooker}

The efficiency of the solar cooker is the ratio of the output power to the input power. The output power is calculated as:

$$
Q_{\text {out }}=\frac{M_{W} C_{w} \Delta T_{\infty-95}}{\Delta t}
$$

...where $M_{w}$ is the mass of water, $c_{w}$ is the specific heat of water, and $\Delta T$ is the temperature difference from ambient to $95^{\circ} \mathrm{C}$. The input power is:

$$
Q_{\text {in }}=\bar{I} A
$$

The equation for the efficiency of solar cooker becomes:

Efficiency $=\frac{\text { outputpower }}{\text { inputpower }}=\eta=\frac{M_{w} C_{w} \Delta T_{\infty-95}}{\bar{I} A \Delta t}$

\section{Results and Discussion}

Different tests were performed to test the performance parameters of a box-type solar cooker made from local material in the climatic conditions of Quetta, Pakistan. The tests were conducted to find the first figure of merit and second figure of merit, cooking power and thermal efficiency as suggested by different researchers in different climates across the world.

\section{Stagnation Test or First Figure of Merit}

The experimentations for the box solar cooker were started from 1 October 2014. For stagnation test $\left(F_{1}\right)$ five days of tests were performed. The cooker was exposed to sunlight with no reflector from 10:00 to 14:00. The solar radiation at the horizontal surface of the glazing of the solar box cooker were recorded with the help of a pyranometer and the thermocouples were used to measure the ambient and plate temperatures. Solar radiation $\mathrm{I}\left(\mathrm{W} / \mathrm{m}^{2}\right)$, ambient temperature $\mathrm{Ta}\left({ }^{\circ} \mathrm{C}\right)$ and plate temperature $\mathrm{Tp}\left({ }^{\circ} \mathrm{C}\right)$ were recorded at stagnation conditions every day. The values of $F_{1}$ for five days of tests were found to be $0.1203,0.1200,0.1208,0.1222$ and 0.1224 , respectively. The average value of $F_{1}$ was 0.1211 , 


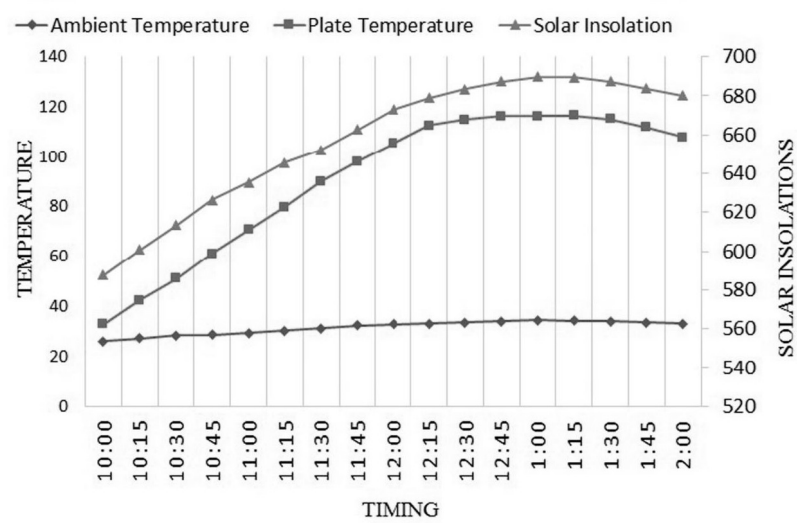

Fig. 4. Variation in the average value of solar radiations, ambient temperature and plate temperature with time for $F_{1}$.

which satisfied the suggested value $\left(0.12-0.16^{\circ} \mathrm{Cm}^{2} / \mathrm{W}\right)$ by the Bureau of Indian Standards [29]. The average variations of ambient temperature, plate temperature and solar insolation with time are shown in Fig. 4.

\section{Sensible Heating Test or Second Figure of Merit}

To find the value of $F_{2}$ (sensible heating test), five days of experiments were conducted. The experiments were started from 10:00 to 14:00. The cooking pot was filled with $2 \mathrm{~kg}$ of water. The cooker was exposed to sun without a reflector. The average value of ambient temperature, water temperature and solar insolation were measured as shown in Fig. 5. The calculated value of $F_{2}$ for five days of tests was found to be $0.53,0.56$, $0.61,0.62$ and 0.58 , respectively. The average value of $F_{2}$ was 0.58 which satisfied the value suggested (0.254-0.490) by the Bureau of Indian Standards (BIS IS13429:2000) and is much better than that reported [11, 23]. Hence the results indicate the good performance of the solar cooker.

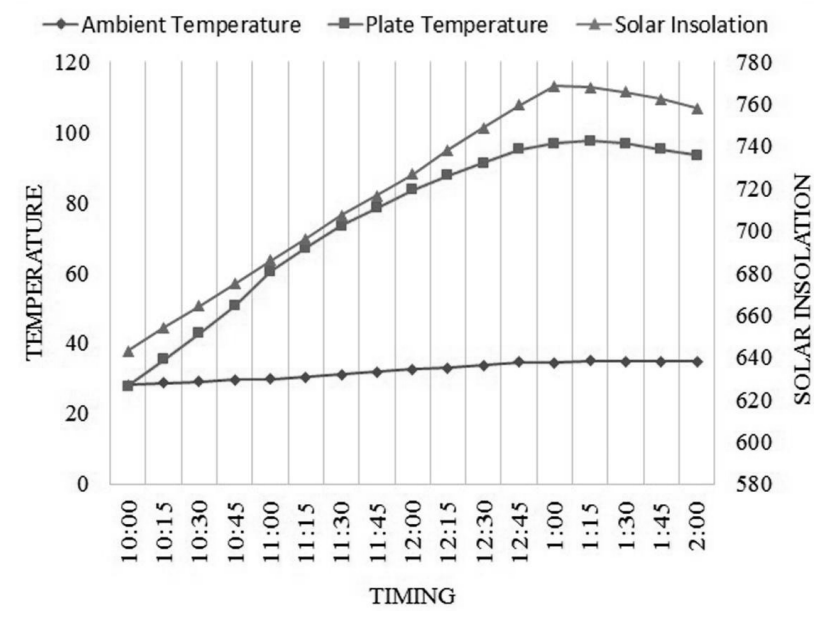

Fig. 5. Variation in average value of solar radiation, water temperature and plate temperature with time for $F_{2}$.

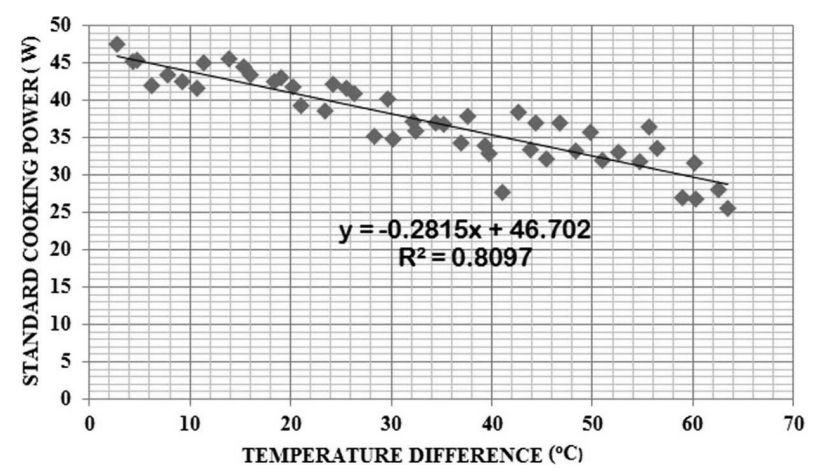

Fig. 6. Standard cooking power of each interval against the temperature difference.

\section{Cooking Power Test}

The cooking power experiments of the box-type solar cooker were conducted at five different days in the month of October 2014. The cooking vessel was filled with $2 \mathrm{~kg}$ of water and the cooker was placed in the sun from 10:00 to 14:00. During the experimentation, the solar radiation, plate temperature, water temperature and ambient temperature were measured in 10-minute intervals. The cooking power and standard cooking power of each interval were calculated. The temperature difference between the initial water temperature and final water temperature of each interval was measured [30]. Values of cooking power and standard cooking power were 40.33 and 37.06, respectively. The standard cooking power of each interval was plotted against the temperature difference of that interval as shown in Fig. 6. A linear regression model was used to find the relationship between standard cooking power and temperature difference in the form of intercept $\mathrm{W}$ and slope $\mathrm{W} /{ }^{\circ} \mathrm{C}$. The coefficient of determination $\mathrm{R}^{2}$ was calculated, and the cooking power at $50^{\circ} \mathrm{C}$ was calculated for each test.

\section{Efficiency Test}

After conducting experiments for the figures of merit and cooking power, five days of experimental

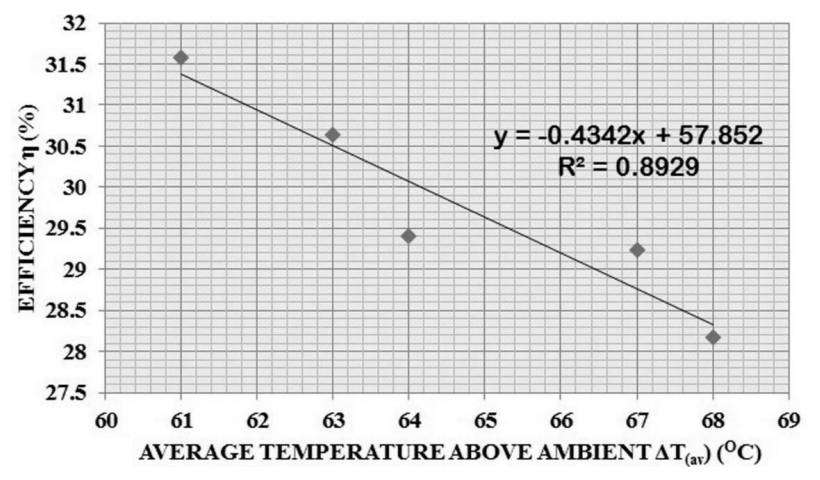

Fig. 7. Efficiency of the solar cooker against average temperature. 
Table. 1. Efficiency of solar cooker.

\begin{tabular}{|c|c|c|c|c|c|c|}
\hline $\mathrm{M}_{\mathrm{w}}(\mathrm{kg})$ & $\mathrm{T}_{\mathrm{w}(\max )}$ & $\mathrm{T}_{\mathrm{a}(\text { ave })}$ & $\Delta \mathrm{T}_{\mathrm{a}(\operatorname{ave})}=\mathrm{T}_{\mathrm{w}(\max )-} \mathrm{T}_{\mathrm{a}(\text { ave })}(\mathrm{C})$ & $\Delta \mathrm{t}(\mathrm{s})$ & $\bar{I}\left(\mathrm{~W} / \mathrm{m}^{2}\right)$ & $\eta(\%)$ \\
\hline 2 & 89 & 28 & 61 & 10800 & 710 & 31.58 \\
\hline 2 & 93 & 30 & 63 & 11400 & 716 & 30.64 \\
\hline 2 & 93 & 29 & 64 & 12000 & 720 & 29.41 \\
\hline 2 & 98 & 31 & 67 & 12600 & 722 & 29.24 \\
\hline 2 & 98 & 30 & 68 & 13200 & 726 & 28.17 \\
\hline
\end{tabular}

tests were conducted for the thermal efficiency of the solar box cooker with a load of $2 \mathrm{~kg}$ of water. Initial and final water temperatures, the temperature difference in the water temperature, time taken between initial and final temperature and solar insolation were recorded to find efficiency. The thermal efficiency of a solar box cooker for $2 \mathrm{~kg}$ of water were calculated as $31.58 \%, 30.64 \%, 29.41 \%, 29.24 \%$, and $28.17 \%$, respectively, as shown in Table 1 . The average efficiency was $29.81 \%$ and was greater than the final limit of suggested thermal efficiency [25].

Fig. 7 shows the graph for efficiency as a function of average temperature above ambient. This gives optical efficiency, i.e., $57.85 \%$ as intercept and overall loss coefficient with $43.4 \%$ as negative of slope with the regression coefficient of 0.89 .

\section{Conclusions}

The box-type solar cooker was made from local materials and tested in the climatic conditions of Quetta, Pakistan. The experimental tests were conducted to find the thermal performance parameters of the box-type solar cooker as suggested by ASAE S580:2003 and BIS IS13429:2000, and the efficiency of the box type solar cooker. According to the ASAE S580:2003 standard, the cooking power and standard cooking power of each interval were calculated and the standard cooking power was plotted against the temperature difference of the same interval. A simple regression was used to find the coefficient of correlation $\mathrm{R}^{2}$. The average calculated value of $\mathrm{R}^{2}$ for the five consecutive sessions was 0.832 . In the ASAE S580:2003 standard the value of $\mathrm{R}^{2}$ should be better than 0.75 , so the calculated value satisfied the ASAE S580:2003 standard. The experimental tests were conducted to find the figures of merits, $F_{1}$ (first figure of merit) and $F_{2}$ (second figure of merit) suggested by the BIS IS13429:2000. From the experimental results the average calculated value of $F_{1}$ for the five consecutive sessions was 0.1211 . The average calculated value of $\mathrm{F}_{2}$ for the five consecutive sessions was 0.58. Both values are in the limit suggested by BIS IS13429:2000. The solar box cooker was experimentally tested to find the value of thermal efficiency for the five consecutive sessions. The average thermal efficiency for the five days was calculated to be $29.81 \%$. All the calculated values satisfied the limits suggested by the test standards. The overall thermal efficiency of the cooker is less than the optical efficiency, i.e., $57.85 \%$. This is concluded on the basis of different performance parameters, i.e., figures of merit, cooking power, standard cooking power and efficiency that the feasibility of the solar box cooker is better in the Quetta region. The amount of solar radiation remains very high in other parts of the country such as Makran, Sibi, and Gawadar, etc., so the solar box cooker can be used throughout the year.

\section{Acknowledgements}

We are greatly thankful to the chairs of the Department of Physics and the Department of Renewable Energy at the University of Balochistan for their valuable suggestions and for providing lab facilities.

\section{Conflict of Interest}

The authors declare no conflict of interest.

\section{References}

1. REN21, Renewables 2017, Global Status Report. URL: http://www.ren21.net/, retrieved on March 10, 2018.

2. REN21, Renewable 2010, Global Status Report. URL: http://www.ren21.net/, retrieved on June 15, 2012.

3. GHANI F., DUKE M., \& CARSON J.K., Effect of flow distribution on the photovoltaic performance of a building integrated photovoltaic/thermal (BIPV/T) collector. Solar Energy, 86 (5), 1518-1530.4, 2012.

4. REN21, Renewables 2014, Global Status Report. URL: http://www.ren21.net/, retrieved on February 14, 2015, 2014.

5. DINCER I., Renewable energy, environment and sustainable development. In Proceedings of the World Renewable Energy Congress V, Florence, Italy 2559), 1998.

6. CHAUDHARY Q.U.Z. A procedure to obtain global solar radiation maps from sunshine duration for Pakistan. Solar \& wind technology, 7 (2), 245-253, 1990.

7. PARK S.R., PANDEY A.K., TYAGI V.V., TYAGI, S.K. Energy and exergy analysis of typical renewable energy 
systems. Renewable and Sustainable Energy Reviews, 30, 105, 2014.

8. MUSSARD M., GUENO A., NYDAL O.J. Experimental study of solar cooking using heat storage in comparison with direct heating. Solar Energy, 98, 375, 2013.

9. YETTOU F., AZOUI B., MALEK A., GAMA A., PANWAR N.L. Solar cooker realizations in actual use: An overview. Renewable and Sustainable Energy Reviews, 37, 288, 2014.

10. CUCE E., CUCE P.M. Theoretical investigation of hot box solar cookers having conventional and finned absorber plates. International Journal of Low-Carbon Technologies, 10 (3), 238, 2013.

11. HARMIM A., MERZOUK M., BOUKAR M., AMAR M. Performance study of a box-type solar cooker employing an asymmetric compound parabolic concentrator. Energy, 47 (1), 471, 2012.

12. LAHKAR P.J., SAMDARSHI S.K. A review of the thermal performance parameters of box type solar cookers and identification of their correlations. Renewable and Sustainable Energy Reviews, 14 (6), 1615, 2010.

13. FAROOQUI S.Z. A gravity based tracking system for box type solar cookers. Solar Energy, 92, 62, 2013.

14. SAGADE A.A., SAMDARSHI S.K., PANJA P.S. Experimental determination of effective concentration ratio for solar box cookers using thermal tests. Solar Energy, 159, 984, 2018.

15. ABU-KHADER M., ABU HILAL M., ABDAllaH S., BADRAN O. Evaluating Thermal Performance of Solar Cookers under Jordanian Climate. Jordan Journal of Mechanical \& Industrial Engineering, 5 (1), 2011.

16. SHAHZAD A., KANWAL T., MAO-GANG H. Design and Development of Efficient Domestic Electric cum Solar Oven. Journal of Basic \& Applied Sciences, 9, 2013.

17. CUCE P.M. Box type solar cookers with sensible thermal energy storage medium: A comparative experimental investigation and thermodynamic analysis. Solar Energy, 166, 432, 2018.

18. ARABACIGIL B., YUKSEL N., AVCI A. The use of paraffin wax in a new solar cooker with inner and outer reflectors. Thermal Science, 19 (5), 1663, 2015.

19. SETHI V.P., PAL D.S., SUMATHY K. Performance evaluation and solar radiation capture of optimally inclined box type solar cooker with parallelepiped cooking vessel design. Energy Conversion and Management, 81, 231, 2014

20. HARMIM A., BELHAMEL M., BOUKAR M., AMAR M. Experimental investigation of a box-type solar cooker with a finned absorber plate. Energy, 35 (9), 3799, 2010.

21. GUIDARA Z., SOUISSI M., MORGENSTERN A., MAALEJ A. Thermal performance of a solar box cooker with outer reflectors: Numerical study and experimental investigation. Solar Energy, 158, 347, 2017.

22. EL-SEBAII A A., IBRAHIM A. Experimental testing of a box-type solar cooker using the standard procedure of cooking power. Renew Energy. 30, 1861, 2005.

23. AL-AZAB T.A., AL-ODAT M.Q., AL-ESSA, F.M. Experimental investigation of the thermal performance of a box-type solar cooker with finned pot in Jordan. Dirasat, Engineering Sciences, 36 (2), 145, 2009.

24. RIKOTO I.I., GARBA I. Comparative analysis on solar cooking using box type solar cooker with finned cooking pot. International Journal of Modern Engineering Research (IJMER), 3 (3), 1290, 2013.

25. EL-SEBAII A.A., AL-HENITI S., AL-AGEL F., ALGHAMDI A.A., AL-MARZOUKI F. One thousand thermal cycles of magnesium chloride hexahydrate as a promising PCM for indoor solar cooking. Energy Conversion and Management, 52 (4), 1771, 2011.

26. KUMAR N., VISHWANATH G., GUPTA A. An exergy based unified test protocol for solar cookers of different geometries. Renewable Energy, 44, 457, 2012.

27. PANDEY A.K., TYAGI V.V., PARK S.R., TYAGI, S.K. Comparative experimental study of solar cookers using exergy analysis. Journal of thermal analysis and calorimetry, 109 (1), 425, 2012.

28. MAHAVAR S., SENGAR N., RAJAWAT P., VERMA M., DASHORA P. Design development and performance studies of a novel single family solar cooker. Renewable energy, 47, 67, 2012.

29. BIS. INDIAN STANDARDS- Solar cookers part (1-3), Bureau of Indian Standards, New Delhi. BIS IS13429:2000.

30. ADAMU A., MOHAMMED A. Modeling the Efficiency Equation of a Solar Box Cooker. International Journal of Research in Science, 2 (3), 207, 2016. 